\title{
ANÁLISIS HISTÓRICO-CULTURAL DEL ALERCE EN LA PATAGONIA SEPTENTRIONAL OCCIDENTAL, CHILOÉ, SIGLOS XVI AL XIX*
}

\author{
M. XIMENA URBINA C."
}

\begin{abstract}
RESUMEN
En este artículo se estudian algunos aspectos de la explotación de los alerzales en Chiloé continental durante el período colonial y hasta comienzos del siglo XX, esto es, las actuales provincias de Llanquihue y Palena, en la Región de los Lagos, y que corresponden a gran parte del área de crecimiento de esta especie arbórea. El corte a pequeña y a gran escala del alerce, con fines comerciales (exportación fuera de Chiloé), fue la principal actividad económica de Chiloé colonial y de aquella provincia durante el siglo XIX, por ser una madera especialmente valorada. Las faenas del corte, su conducción, transporte y comercialización, y sobre todo el tipo humano del tablero, formaron parte de un modo de ser de los habitantes de Chiloé, una manera de entender y relacionarse con su territorio. El objetivo es destacar la importancia histórica y cultural de este árbol y su madera, y la cultura material e inmaterial asociada a él. A base de distintos tipos de documentación colonial -editada y de archivo- e información generada por observadores externos, describiremos la modalidad de esta actividad y oficio. El corte del alerce tuvo dos etapas en el período señalado: una "artesanal" y una "empresarial", y dio origen a un vocabulario, un oficio y un estilo de vida, el del tablero chilote.
\end{abstract}

PALABRAS CLAVE: Alerce, Chiloé, Patagonia, Colonia.

\section{HISTORICAL-CULTURAL ANALYSIS OF LARCH IN THE WESTERN SEPTENTRIONAL PATAGONIA, CHILOÉ, XVI-XIX CENTURIES}

\footnotetext{
ABSTRACT

In this article, different aspects of larch grove exploitation in continental Chiloé is analysed from the colony period through early XX century, i.e. the provinces currently known as Llanquihue and Palena at the Los Lagos region, and which comprise most of the growing area for this tree species. Small and

Proyecto de Investigación Individual, 2011, de la Direccion de Investigación, Vicerrectoría de Investigación y Estudios Avanzados de la Pontificia Universidad Católica de Valparaíso. La investigación es también fruto de la "Beca de Formación Permanente", otorgada por la Fundación Carolina (España), para una estancia de investigación en la Escuela de estudios Hispanoamericanos, en Sevilla, durante febrero de 2011. Agradezco la colaboración en la recopilación de ciertas fuentes al Sr. Boris Araya Valencia, estudiante de magíster en Historia, y al Sr. Nicolás Gorigoitía Abott, licenciado en Historia ambos de la P. Universidad Católica de Valparaíso.

* Doctora en Historia, profesora del Instituto de Historia, Pontificia Universidad Católica de Valparaíso, Chile. maria.urbina@ucv.cl
} 
large-scale larch felling for commercial purposes (exports outside Chiloe) represented the main economic activity for the colonial Chiloé and the province during the XIX century, as it was regarded as a highly valuable wood. Felling works, management, transportation and commercialization, and above all the human type of the scenario shaped in a way the behaviour of Chiloe inhabitants, a form to understand and relate with their territory. The objective is to emphasize the historical and cultural significance of this tree and its wood, along with its material and immaterial culture. Based on diverse colonial documents, both edited and filed, and information generated by external observers, we will describe this activity and trade methods. Larch felling involved two stages for the mentioned period: an "artisanal" stage and a "business" stage, which gave rise to a vocabulary, a trade and a way of life: the Chilote stage.

KEY WORDS: Larch, Chiloé, Patagonia, Colony.

\section{BOSQUES EN CHILOÉ}

En la segunda mitad del siglo XIX se recorrían los interiores más accesibles de la isla grande de Chiloé, Patagonia Occidental Insular, y se talaban secciones de un bosque casi impenetrable. Por entonces, los grandes bosques, en particular los alerzales de Piuchué y Pirulil en las zonas adyacentes al río Chepu, lagos Huillinco y Cucao, y la espesa montaña de los litorales suroriental y sur de la isla grande de Chiloé, habían sido recorridas en parte y conocido ya el hacha y el fuego. Aún así, Chiloé seguía teniendo la fisonomía de intenso verdor de los siglos coloniales ${ }^{1}$. En 1897, Aurelio Lagunas, ayudante de la comisión que encabezaba Roberto Maldonado para estudiar la geografía e hidrografía de Chiloé, decía: toda la Isla Grande se halla totalmente cubierta de una espesa vegetación arborescente y apretada, estando a la vez entremezclada por arbustos y malezas... [de manera que] forma un espeso colchón en el cual no es dable penetrar sin el machete de monte, que es necesario usar incesantemente para abrirse paso a duras penas y hacer lento camino ${ }^{2}$. Maderas de lingue, olivillo, luma; en las orillas del río Chepu se extendía un muy escarpado, accidentado y enmarañado bosque de tepuales; ciruelillos, avellanos y laureles, trau-trau, alerces y cipreses. En la laguna de Cucao los bosques llegaban hasta sus orillas,

1 Darwin, Charles, 1945, Viaje de un naturalista alrededor del mundo, Librería El Ateneo, Buenos Aires, cap. XII, p. 330 .

2 Lagunas, Aurelio, Memoria del ayudante de la comisión, en Maldonado, Roberto, 1897, Estudios geográficos e hidrográficos sobre Chiloé, Establecimiento poligráfico Roma, Santiago, p. 316. aunque los cipreses se alzaban como columnas cenicientas y desprovistas de todo follaje a causa de haber sido incendiado el bosque ahora ocho años pasados para facilitar su explotación, precisa Maldonado en $1897^{3}$.

Todavía en 1926 Schwarzenberg describía la Isla Grande como cubierta de exuberante vegetación arbórea, pero advertía que la montaña iba desapareciendo paulatinamente de los alrededores de los centros de población. Y tal como en el período colonial, las áreas más humanizadas, como las costas del canal de Chacao y la franja oriental de la isla de Chiloé, se apartaban de las selvas cediendo su lugar a tierras de cultivo ${ }^{4}$. Que la vida chilota se haya concentrado en la franja costera tiene su sentido. Schwarzenberg escribía que el mar y el marisco ejercen un gran atractivo sobre el chilote, y por eso la admirable subdivisión de la propiedad en las costas accesibles y abundantes en peces y mariscos. El interior, en cambio, está despoblado o habitado por escasas personas, es de poco cultivo, y por lo mismo, cerrado de monte $e^{5}$, porque la apertura del bosque produjo sólo estrechos claros abiertos junto a las orillas, que permitían a las familias combinar la marisca y pesca con el cultivo de cortos sembradíos de papas y provisión de leña y madera. El trabajo del corte y quema del sotobosque y del bosque casi impenetrable, vecino a la casa, era una tarea casi titánica, un espacio en que visiblemente el hombre sólo tiene éxitos parciales o victorias efímeras sobre el bosque, de modo que el conjunto del paisaje

Maldonado, Roberto, op. cit., p. 176.

4 Schwarzenberg, Jorge y Arturo Mutizábal, 1926, Monografía geográfica e histórica del archipiélago de Chiloé, Editorial Nascimento, Santiago, p. 21.

5 Ibidem, p. 22. 
aparece particularmente inacabado, observó el geógrafo francés Philippe Grenier en 19846.

En esos interiores, y en la tierra firme continental al norte y al oriente del archipiélago de Chiloé, actuales provincias de Chiloé, Llanquihue y Palena, Región de Los Lagos, la biogeografía alcanza su mayor expresión con los alerces (Fitzroya cupressoides), robustos árboles que pueden alcanzar 5 metros de diámetro ${ }^{7}$, aunque a veces la documentación colonial señala 10 metros. Con sus hasta 50 metros de altura, el alerce es el rey indiscutido del nutrido bosque chilote: el príncipe de los árboles de Chile, escribió el jesuita Diego de Rosales ${ }^{8}$. Recto y espigado, impone con mucho su gigantesca columna blanquizca por sobre el bosque que le rodea, superando por 20 ó 30 metros a mañíos, coigües y robles. Es una conífera endémica de la Patagonia, que se encuentra entre Corral y Chiloé, en la cordillera de la costa; y en las estribaciones de cordillera de los Andes, entre el volcán Puntiagudo y Chaitén. Investigaciones recientes muestran que durante la última glaciación los bosques de alerce habrían tenido una distribución más amplia y continua que en la actualidad, ocupando las zonas bajas de la depresión intermedia de las provincias de Llanquihue y Chiloé, lo que hoy está cubierto por el mar interior ${ }^{9}$. Su desarrollo es extremadamente lento: su tronco crece entre 0,6 y 1,6 milímetros al año ${ }^{10}$, y esto es en promedio un centímetro de espesor cada 10 años. Todas las descripciones de los siglos coloniales coinciden en señalar que el alerce -que los indígenas llamaban

6 Grenier, Phillipe, 1984, Chiloé et les chilotes. Marginalité et dépendance en Patagonie chilienne, Ediciones EDISUD, Aix en Province, France, p. 29.

7 Donoso, Claudio, Renato Grez y Víctor Sandoval, 1990, Caracterización del tipo forestal alerce, Bosque 11 (1): 2134.

8 Rosales, Diego de, 1877, Historia General del Reino de Chile, Flandes Indiano, Imprenta El Mercurio, Valparaíso, Tomo I, p. 222

9 Villagrán, Carolina et al, 2004, Paleodistribución del alerce y ciprés de las Guaitecas durante períodos interestadiales de la Glaciación Llanquihue: provincias de Llanquihue y Chiloé, región de Los Lagos, Chile, Revista Geológica de Chile, 31 (1):133-151.

10 Lara, Antonio, 1988, Alerces: gigantes milenarios del bosque chileno, en Hoffmann, Adriana (editor), La tragedia del bosque chileno, Ocho Libro Editores, Santiago, p. 96. En este artículo el ingeniero forestal Antonio Lara ofrece los resultados de las investigaciones sobre la conservación del alerce y los desafíos que ello representa. lahuan- es uno de los árboles más bellos y esbeltos de América. Se ven como inmensos palos rectos en forma de columnas desnudas, porque las ramas sólo nacen a mucha altura y son poco tupidas, con hojas pequeñas. Así, el alerce se yergue como el señor de los bosques australes maravillando por su altura y grosor. La edad de estos gigantes se ha calculado en 2.500 años, pero pueden vivir más de $3.600^{11}$.

Aunque Roberto Montandón escribió en 1945 que del alerce se tienen fundadas razones para creer que ya hacía el objeto de transacciones comerciales entre Chiloé y el Perú en la época precolombina ${ }^{12}$, no hay antecedentes al respecto. La prueba más antigua de utilización del alerce la da el sitio arqueológico de Monte Verde, donde hay evidencias del uso de esta madera y de la fabricación de artefactos domésticos con ella, de poblaciones que vivieron 13.000 años antes del presente. Los huilliches previos al período de contacto ocupaban tanto el alerce como otras maderas, en estrategias de adaptación que se hunden en el tiempo. Utilizaban el alerce para utensilios, medicina, herramientas o armas de defensa, que obtenían de los bosques de alerce a baja altura respecto del nivel del mar ${ }^{13}$.

A fines del siglo XVI era ya la madera símbolo de Chiloé, digno de figurar como el emblema de estas provincias australes, dijo Francisco Fonck en 1900, siendo sus tablas las más apreciadas en el reino de Chile y en el Perú, por ser una de las maderas más nobles, elásticas y livianas de cuantas ofrece el continente, además de muy resistente a la humedad y al agua. Su tronco es rendidor, con una corpulencia que aventaja a cualquier ejemplar de otra especie. A principios del siglo XVIII fray Gregorio de León señalaba que salían comúnmente 600 tablas de su tronco, que lo estimaba en seis brazas de diámetro ${ }^{14}$, y eso es 10,02 metros, aunque el piloto español José de Moraleda, aseguraba a fines de ese

11 Idem.

12 Montandón, R.A., 1945, El alerce, preocupación ancestral del chilote, En Viaje 146: 182-183, p. 182.

13 Morales, Héctor, 2006, La cultura del alerce, en Comisión Nacional del Medio Ambiente, Conservación de la biodiversidad de importancia mundial a lo largo de la costa chilena, Ocho Libro Editores, Santiago, pp. 116-123, p. 116.

14 Fray Gregorio de León, citado en un papel anónimo posterior, probablemente a mediados del siglo XVII. Biblioteca Nacional (en adelante BN), Santiago, Manuscritos Medina (en adelante MM), Tomo 99. 
mismo siglo que se habían visto sacar mil tablas de un solo alerce; y coincide con Bernardo Philippi, quien promedia entre 500 y 600 tablas por árbol, para $1842^{15}$, aunque según Fonck los más gruesos que se conocían en su época (año 1900) eran de 5 metros, como los que quedan en la actualidad ${ }^{16}$.

Que Chiloé se haya conservado poblado de españoles después de 1600, en que con una gran rebelión los mapuches y huilliches expulsaron a los españoles del territorio entre Concepción, por el norte y Chiloé (excluído) por el sur, se debió en buena parte a la existencia de sus extensas superficies boscosas que permitieron su explotación y comercio $y$, por ende, las razones para permanecer ${ }^{17}$. El alerce llegó a ser la moneda de la provincia y el efecto que movía el comercio con el Perú. La producción de tablas estaba orientada casi exclusivamente a ese fin, excepto las cortas cantidades que de cuando en cuando se necesitaban para levantar o reparar iglesias en el archipiélago, y la construcción de embarcaciones. El corte y aprovechamiento era libre y espontáneo, porque nadie tenía exclusividad en los alerzales, por ser tierras lejanas y sin propietario. Como los montes y pastos, el disfrute de los bosques de alerce fue del común en Chiloé durante el período colonial, pero desde la incorporación de Chiloé a Chile, en 1826, esto cambió. El Estado inició las mensuras y se aceleraron las compras, remates y las grandes concesiones de tierras a compañías foráneas para la explotación, sobre todo maderera, y por lo tanto, para ganar al bosque un poco de terreno de siembras se hacía necesario la exhibición de títulos de propiedad.

\section{LOS ASTILLEROS}

Los lugares de corte eran llamados astilleros, y desde el siglo XVII había tres áreas principales. En primer lugar, en la jurisdicción de Calbuco (que era un fuerte y un pueblo), donde estaban los astilleros más antiguos y de mayor producción. Cortaban

15 Philippi, Bernardo, 2002, Relación del descubrimiento del lago Llanquihue (1842), en Pioneros del Llanquihue, 1852-2002, Liga Chileno-Alemana, Santiago, p. 20.

16 Lara, Antonio, op. cit., p. 96.

17 Urbina, Rodolfo, 1986, Las tablas de alerce y los antiguos tableros chilotes, Creces 12: 19-21. Este artículo de dos páginas es el único estudio histórico publicado sobre el alerce. alerce principal pero no exclusivamente, los habitantes de Calbuco y cercanías. Sus destinos eran distintos lugares del fiordo de Reloncaví, al que se accedía desde la Isla Grande por la ruta de la isla Tabón, como lo vio Tomás O"Higgins cuando visitó Chiloé en $1797^{18}$. Allí se situaban los alerzales de Cayenel, río Coihuín, estero de Coitué y La Manga, entre 8 y 9 leguas al noreste de Calbuco. El de más antigua explotación era el sector de Melipulli, vecino a Calbuco y cercano al puerto de Chacao, este último sede del gobernador y lugar de la mas importante feria de Chiloé durante los siglos XVII y gran parte del XVIII. Melipulli mantuvo su actividad, $e$ incluso, durante el verano de 1842 podían verse de 27 a 30 casuchas con una población temporal de más de 200 almas, que durante el día abandonaba el sitio para internarse al corte $e^{19}$. Cercano de allí, Canutillar, ribera izquierda del estero de Cochamó, era en el siglo XIX asiento de explotadores del bosque de alerce que abunda en los contornos, dice el diccionario de Asta-Buruaga, de $1899^{20}$, así como también las riberas del cercano río Coihuín, al que también se le solía llamar río de Chamiza por ser ese el nombre de un embarcadero de maderas que estaba situado en su parte superior ${ }^{21}$. Las fuentes coloniales y del siglo XIX coinciden en señalar que el sector de Reloncaví era el de mayor actividad de corte.

En segundo lugar, Maullín, partido de Carelmapu, especialmente los astilleros a los que se accedía por el río Palihué, alerces cercanos a la costa del Pacífico. Estos, a fines del siglo XVIII ya mostraban señas de estar agotándose, como apunta Moraleda al notar que desde este sector sólo se extraen 25 a 30.000 tablas al año, del total las 200.000 que exportaba Chiloé ${ }^{22}$. Aún así, un siglo más tarde, Asta-Buruaga dice que abunda el alerce en el Departamento de Carelmapu, en los contornos de Puerto Godoy, y también en la pequeña caleta Cóndor, en el Departamento de Osorno, donde se señalan alerzales por esas fechas, como en las

18 Viaje del capitán de ejército don Tomás O"Higgins de orden de virrey de Lima, el marqués de Osorno, 1796-1797. Archivo Nacional de Santiago, Fondo Antiguo, Vol. 33, fjs. 29.

19 Philippi, Bernardo, op. cit., p. 19.

20 Asta-Buruaga, Francisco, 1899, Diccionario geográfico de la república de Chile, Segunda Edición, Santiago, p. 115.

21 Ibidem, p. 155.

22 Moraleda, José, 1888, Exploraciones geográficas e hidrográficas, Imprenta Nacional, Santiago, p. 216. 

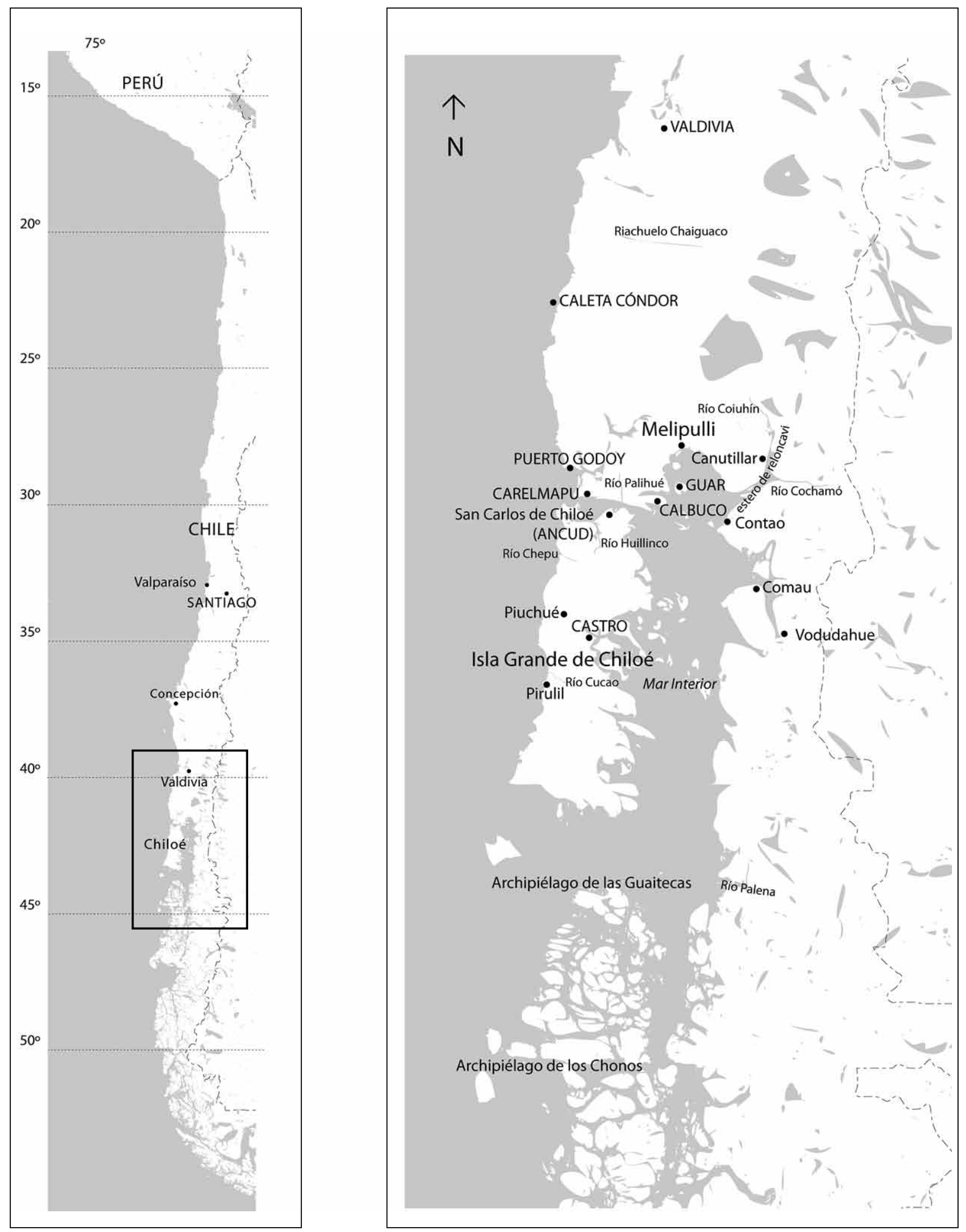

Fig. 1. El corte del alerce en Chiloé 
partes mas altas del recorrido que hace el riachuelo Chaiguaco, todo en la franja costera de la zona ${ }^{23}$.

Por último, un tercer lugar de corte eran Comau y Vodudahue, fiordos al oriente de Chiloé insular (atual provincia de Palena), que era un sector explotado especialmente desde la segunda mitad del siglo XVIII, en los parajes de Contao, Reñihue y Leteu. Comau era uno de los más antiguos lugares de corte, por ser el área de alerces más próxima a Chiloé, que estaba enfrente del mar interior. Aún así, en 1900 decía el explorador Francisco Fonck que en Comau la explotación del alerce se hace aun hoy día en escala considerable $e^{24}$. En cierta forma, cada isla o pueblo chilote explotaba su propia zona enfrente, en el continente. Los de Calbuco e islas vecinas iban a la boca del estero de Reloncaví25; los de Chonchi, Queilen, Curaco de Vélez, Dalcahue y gente de todos los pueblos se repartían entre los fiordos hacia el este.

\section{TABLAS, TABLONES, VIGAS Y VIGONES: LA MONEDA DE LA PROVINCIA, PERO EL RETROCESO DEL BOSQUE}

A medida que pasaban los años, los alerzales ya no estaban en la misma costa, que había sido depredada desde el siglo XVI ${ }^{26}$. En el siglo XVIII los tableros se venían quejando del penoso trabajo de talar 4, 6 u 8 leguas al interior, montaña arriba, o más, y en 1743 el cabildo de Castro se lamentaba porque los alerzales están muy acabados [...] y los que hay, muy retirados a lo más fragoso y recóndito de las cordilleras ${ }^{27}$. A mediados del siglo XIX, en el sector de Melipulli, de antigua explotación forestal, sólo eran visibles a mucha distancia los alerces -que, dice Philippi, antes llegaban hasta

23 Asta-Buruaga, Francisco, op. cit., pp. 285, 173 y 217.

24 Fonck, Francisco, 1896, Diarios de fray Francisco Menéndez, T. I, Viajes a la cordillera (segundo viaje, 1786), Imprenta Niemeyer, Valparaíso, p. 20.

25 Steffen, Hans, 2008, Patagonia Occidental. Las cordilleras patagónicas y sus regiones circundantes, reedición a cargo de Eugenio Aspillaga y Luis Catalán, de la edición de 1844 de la Universidad de Chile, Santiago, T. I, p. 95.

26 Sobre el retroceso del bosque en Chile véase la obra del ingeniero forestal Luis Otero Durán, 2006, La huella del fuego. Historia de los bosques nativos. Poblamiento y cambios en el paisaje del sur de Chile, Pehuen Editores, Santiago.

27 El cabildo de Castro. Castro, 16 de abril de 1743. Archivo General de Indias, Sevilla, Audienia de Chile, Legajo 102. las orillas del mar-, lo que obligaba a los tableros a buscar y trabajar los troncos abandonados ${ }^{28}$. Durante ese siglo la explotación económica de los bosques para nuevas y mayores demandas fue la principal actividad humana en los valles occidentales de la Patagonia, desde el golfo de Reloncaví hasta el valle inferior del río Palena ${ }^{29}$. La mayor escala de la explotación significó un retroceso de alerces y cipreses, tanto que a fines del siglo XIX se reconocía que el alerce sólo se encontraba en las montañas más apartadas y por lo general a considerable altura, mientras que en otros tiempos poblaba en gran cantidad también las llanuras ${ }^{30}$, aunque también había bosques que en muchos puntos apenas han sido tocados y representan una riqueza importante para la región ${ }^{31}$. La razón de la desaparición del bosque estaba en el intenso corte, pero también en que para despejar terrenos ya explotados, con el fin o de transitar por ellos a bosques más alejados, o de hacer potreros cultivables, se prendía fuego al bosque, quemándose también los retoños de los alerces. Aún así, dice Fernando Torrejón y su equipo, que a pesar de que las transformaciones ecológicas impuestas por la colonización española en Chiloé fueron muy importantes, las mismas se vieron atenuadas por las condiciones biogeográficas del territorio, y así, a fines del XVIII gran parte de Chiloé continental e insular mantenía unas características medioambientales prehispánicas ${ }^{32}$.

En los siglos XVII y XVIII las tablas de alerce eran apreciadas en Lima, único lugar con el que los chilotes practicaban el comercio, cuando en verano llegaban los barcos desde el Callao a la feria de Chacao. Estas tablas fueron la moneda de Chiloé colonial, donde no existía circulante sino que el comercio se practicaba como trueque, mucho más valiosa que los otros productos que se exportaban, como jamones ahumados, pescado seco o ponchos, y que se intercambiaban por azúcar, sal, ají, añil,

28 Philippi, Bernardo, op. cit., pp. 19 y 21

29 Véase, Torrejón, Fernando, 1996, Ecohistoria y destrucción en Chiloé continental: el caso del valle Vodudahue, 17001996, en Bases históricas del desarrollo regional de Chile, Facultad de Filosofía, Universidad de Chile, Santiago.

30 Steffen, Hans, op. cit., T. I, p. 45

31 Idem.

32 Torrejón, Fernando, Marco Cisternas y Alberto Araneda, 2004, Efectos ambientales de la colonización española desde el río Maullín al archipiélago de Chiloé, sur de Chile, Revista Chilena de Historia Natural 77: 661-677. 
aguardiente, ropa de la tierra y ropa de Castilla. Aun así, y a pesar de lo ponderada y demandada de su madera, y del mercado existente el Perú, se vendía barata y no permitió a Chiloé salir de la pobreza, sino tan sólo subsistir. Señala el ingeniero Lázaro de Ribera, en 1783, que una tabla de alerce valía en Chiloé 11/4 real, pero que en Lima valía 4 reales, sobreprecio que enriquecía a unos cuantos, lo que ocurría también con los demás efectos salidos de Chiloé $^{33}$. A lo largo del siglo XVIII, de más activo comercio, hubo variación tanto en el precio como en las dimensiones de las tablas. A mediados de ese siglo se fijaron sus medidas en $2 \frac{1}{1} 2$ varas de largo por 12 pulgadas de ancho, y avaluadas cada una en $2 \frac{1}{2}$ reales de plata. Cuando por real cédula de 1780 se abolió en Chiloé el servicio personal de los indígenas, se fijó en 5 pesos el tributo anual de cada uno, que como súbditos de la Corona debían depositar en las Cajas Reales. Este se pagaba por no haber circulante- en 40 tablas de alerce, recibiéndose a un real cada una ${ }^{34}$. Fray Francisco Menéndez, que escribe en 1786, dice que el valor de la tabla no alcanzaba los 3 reales $^{35}$, mientras que un par de años después, las dimensiones requeridas eran de 3 varas de largo, un palmo de ancho $(8,2$ pulgadas) y una pulgada de grosor, es decir, más largas pero menos anchas que antes, aunque su valor había disminuido un real, siendo ahora de 1 y 3/8 real de plata ${ }^{36}$, lo que es la mitad de la cifra anterior. Las fuentes dan valores dispares, porque en 1790 se registra el precio de $3 / 4$ de real, y así, 8.365 tablas de alerce se vendieron a un barco de Lima en 809 pesos y 4 1/2 reales $^{37}$. Fray Pedro González de Agüeros, que fecha su Descripción Historial de Chiloé en 1791 dice las tablas de alerce medían 4 varas de largo, 6 a 7 pulgadas de ancho y $1 \frac{1}{1 / 2}$ de

33 Discurso que hace el alférez don Lázaro de Ribera, ingeniero delineador, sobre la provicia de Chiloé... (1782), en Anrique, Nicolás, 1897, Cinco relaciones jeográficas e hidrográficas que interesan a Chile, Imprenta Elzeviriana, Santiago, p. 17.

34 Fonck, Francisco, 1900, Viajes de fray Francisco Menéndez a Nahuelhuapi, Imprenta Niemeyer, Valparaíso, p. 404 (nota de Fonck).

35 Fonck, Francisco, Diarios de fray Francisco Menéndez, T. I, Viajes a la cordillera, op. cit, p. 23.

36 Moraleda, José, op. cit., p. 215.

37 Archivo General de la Nación (en adelante AGN), Perú, Fondo Cajas Reales, Cajas Reales de Chiloé, Legajo 411, cuadernos 143 a 156, 1789-1790. grueso $^{38}$. La explicación en la depreciación de la tabla y las variaciones de sus medidas está en un comercio con Lima que se fue haciendo cada vez más desventajoso ${ }^{39}, y$, por lo mismo, se fueron reduciendo sus medidas, como lo explica el marino español José de Moraleda. Las tablas eran vendidas individualmente por los hacheros, y se dice en el siglo XVIII que el principal comprador era el propio gobernador de la isla, que las acumulaba durante el año para embarcarlas todas juntas a Lima: así hacía su ventajoso negocio, porque las compraba muy baratas y las pagaba en especies ${ }^{40}$. Tenemos como dato que en 1842 las tablas de alerce en Melipulli se hacían de 9 pies de largo (3 varas) por 9 pulgadas de ancho, y entre $1 / 2$ y 1 pulgada de grueso ${ }^{41}$. Un listado de las maderas exportadas en Chiloé en 1843 da cuenta de los tipos acostumbrados para el alerce: tablas corrientes, tablas de a 4 varas y 1 pulgada canto, tablas del doble grueso, tablones de 4 varas, tablones comunes, y viguetas ${ }^{42}$. Alfredo Weber, que publica en 1903, dice que el valor de la tabla es de 7,50 pesos el ciento, y que sus dimensiones son de $21 / 2$ de largo, por $1 / 2$ pulgada de grueso y 6 de ancho ${ }^{43}$.

En cuanto al volumen, en 1782 se exportaban anualmente 230.000 tablas de alerce ${ }^{44}$, y 200.000

38 González de Agüeros, Pedro, 1988, Descripción historial de Chiloé, 1791. Introducción y notas de Isidoro Vázquez de Acuña, Santiago, Instituto de Investigaciones del Patrimonio Territorial de Chile, Universidad de Santiago, p. 125.

39 Urbina, Rodolfo, 1990, El modo de comerciar de los chilotes a fines del siglo XVIII, en Bravo Acevedo, Guillermo (editor), Economía y comercio en América Hispana, Serie Nuevo Mundo: Cinco Siglos, № 5, Universidad de Chile, Santiago, p. 108 .

40 Güell, Segismundo, Noticia breve y moderna del Archipiélago de Chiloé, de su terreno, costumbres de sus indios, misiones, escrita por un misionero de aquellas islas en el año 1769 y 70, en Hanisch, Walter, 1982, La isla de Chiloé, capitana de rutas australes, Santiago, Academia Superior de Ciencias Pedagógicas de Santiago, Apéndice Documental, Documento III, p. 245,

41 Philippi, Bernardo, op. cit., p. 19

42 Designación del derecho de muelle que deben pagar al tiempo de su extracción las diferentes maderas y frutos de la provincia, AN, Intendencia de Chiloé, Vol. 10, Ancud, 28 de julio de 1843

43 Weber, Alfredo, 1903, Chiloé: su estado actual, su colonización, su porvenir. Con un mapa que indica las colonias extranjeras y los terrenos colonizables, Imprenta Mejía, Santiago, p. 63.

44 Discurso que hace el alférez Lázaro de Ribera, op. cit. 
dice Moraleda en el mismo decenio ${ }^{45}$, aunque sólo 70.000 refiere Vicente Carvallo y Goyeneche, que termina de escribir su obra en la década de $1790^{46}$. Eso si, el piloto español estuvo durante varios años en Chiloé, mientras que Carvallo residía en Valdivia, y acabó su obra una década después de haberla iniciado, por lo que los datos pueden ser erróneos o haber quedado obsoletos, aunque González de Agüeros, en 1791, dice que salían hacia el Callao en promedio 50 ó 60.000 tablas de alerce ${ }^{47}$. Los barcos peruanos iban siempre sobrecargados, y zozobraban en el canal de Chacao o en el golfo de Ancud. Podían embarcarse 46.000 tablas de alerce en un solo barco a fines del siglo XVIII, como las que en abril de 1790 llevaba la fragata Carmen al Callao ${ }^{48}$. La fragatilla Ventura conducía 30.000 tablas de alerce -9.400 de cuenta del rey y 19.856 de particulares-, además de otros efectos $^{49}$, mientras que con 18.000 se cargó el paquebot Santo Domingo, del comercio con el Callao, pero que naufragó ${ }^{0}$. En 1786, a bordo de una fragata del Perú, El Gran Poder, un particular llevaba 2.000 tablas de alerce a Pisco, para la construcción de la iglesia de Chincha ${ }^{51}$. También se conducían a Valdivia en embarcaciones menores, para desde allí hacer el comercio con Perú, como lo hacía el falucho del rey, que en 1782 se aprestaba para conducir 2.000 tablas de alerce a la plaza, lo que era una carga excesiva ${ }^{52}$.

La madera, que se valoraba por su resistencia a la humedad y a la intemperie era exportada en forma de vigones, vigas, viguetas, tablones, tablas y duelas: en 1781 salieron de Chiloé, además del alerce en tablas, 1.000 de vitola de alerce, 70 de ciprés, 642 de avellano, 864 de laurel, 732 cuarterones de alerce, 497 lumas y 405 botavaras y remos ${ }^{53}$. José Rodríguez Ballesteros, para el período 1813-1826, vio exportarse de un número considerable de tablas,

45 Moraleda, José, op. cit., p. 216.

46 Carvallo y Goyeneche, Vicente, 1865, Descripción históricojeográfica del reino de Chile por don Vicente Carvallo $i$ Goyeneche, precedida de una biografía del autor por don Miguel L. Amunátegui, en Medina, José Toribio, Colección de historiadores de Chile y de documentos relativos a la historia nacional, Tomos VIII, IX y X, Santiago, T. IX, p. 207.

47 González de Agüeros, Pedro, op. cit., p. 125.

48 Fonck, Francisco, Viajes de fray Francisco Menéndez a Nahuelhuapi, p. 164 (nota de Fonck)

49 Ibídem, p. 521.

50 Moraleda, José, op. cit., p. 412.

51 AGN, Perú, Cajas Reales de Chiloé, Leg. 407, cuad. 108

52 Moraleda, José, op. cit., p. 231.

53 Discurso que hace el alférez Lázaro de Ribera, op. cit.. tablones, cuartones, viguetas y vigas de alerce -que llama también cedro rojo-, lumas, cipreses, lingue, avellano, laurel, ralral, todas maderas útiles para fabricar casas y buques, como vio construir en sus astilleros continuamente goletas, bergantines y fragatas de diferentes toneladas ${ }^{54}$, y también canoas, lo que era de antigua data y común actividad en Chiloé, y para lo cual citamos sólo un caso: en uno de los viajes de Francisco Menéndez a la cordillera de Chiloé, se cortó un alerce del que se sacaron dos canoas, la una de $81 / 2$ varas de largo y la otra de $61 / 2^{55}$. Pero también se le empleaba en la fabricación de vasijas. Además, la rectitud de sus fibras y la poca densidad de su masa, hacía a la madera del alerce ideal para la fabricación de instrumentos de cuerda ${ }^{56}$. Todo esto aunque en Chiloé, además de las tablas para la edificación, se utilizaba sobre todo el alerce para hacer tejas con que techar y cubrir casas, fogones, iglesias, y en general, todas las construcciones, lo que constituyó al tejeuelero como un oficio, tal como lo era el tablero ${ }^{57}$. Parte de los abastecimientos para refundar Valdivia en 1645 eran 6.000 tablas de Chiloé ${ }^{58}$, y consta más tarde que, en 1695, el palacio del gobernador de esa plaza se construyó con techo de tablas traídas de Chiloé ${ }^{59}$, como se continuó haciendo luego, al enviarse tablas de alerce para la ejecución de nuevas obras de defensa de la plaza, requiriendose, al menos

54 Rodríguez Ballesteros, José, 1901-1904, Revista de la guerra de independencia de Chile, 1813-1826, en Colección de historiadores y documentos relativos a la independencia de Chile, Imprenta Cervantes, Santiago, Vol. 6, p. 365

55 Fonck, Francisco, Diarios de fray Francisco Menéndez, Tomo I, Viajes a la cordillera, op. cit., p. 61. Véase Urbina, M. Ximena, 2009, La frontera de arriba en Chile Colonial. Interacción hispano-indígena en el territorio entre Valdivia y Chiloé e imaginario de sus bordes geográficos, 1600-1800, Centro de Estudios Diego Barros Arana, de la Dirección de Bibliotecas, Archivos y Museos, y Ediciones Universitarias de Valparaíso, cap. 3.

56 Memoria del ayudante de la comisión, Sr. Aurelio Lagunas, apéndice A, en Maldonado, Roberto, op. cit., p. 317.

57 Véase Montiel, Felipe, 2006, Los últimos constructores de artilugios de madera en Chiloé, Gobierno Regional de Los Lagos, y Conaf.

58 Guarda, Gabriel, 1990, Flandes Indiano. Las fortificaciones del reino de Chile, 1541-1826, Santiago, Ediciones Universidad Católica de Chile, p. 63.

59 Guarda, Gabriel, 1974, El gobierno de Valdivia (1645-1820), Boletín de la Academia Chilena de la Historia 88: 117-162, p. 139. Guarda cita a AN, Fondo Capitanía General, Vol. 550,56 . 
en 1785 , un total de 50.000 para los proyectos del castillo de Niebla, de Amargos, del cerro Chorocamayo, y castillo de Corral ${ }^{60}$. Asimismo, como auxilio en tablas para mantención se le asignó a la misión de Nahuelhuapi, en su refundación de 1713, un socorro anual de 500 tablas de alerce mientras durara la construcción de los edificios de la misión ${ }^{61}$.

En el siglo XIX la explotación del alerce adquirió mayor importancia porque la economía provincial se sostenía a base de ese producto. Alcanzó su punto más alto desde que el ferrocarril demandó durmientes y postes para el telégrafo, siendo los primeros de ciprés y los segundos, normalmente, de alerce, así como la fabricación de embarcaciones para empresarios armadores de los puertos chilenos. Se aseguraba que el alerce era inmejorable, por su dureza, para hacerse las cubiertas de los buques de guerra y en general, las construcciones navales, aunque con la precaución de no usar esa madera para arboladura, vergas o votalones, debido a su elasticidad ${ }^{62}$. Quienes operaban el tráfico no eran ya los gobernadores, comerciantes o encomenderos de Chiloé colonial, sino empresarios instalados en la isla grande, que enviaban a sus operadores tableros a la tala en la Cordillera $^{63}$. El inicio de la explotación y su ocaso, volúmenes y mercados, operarios y modalidades, son un tema pendiente de estudiar. Claudio Gay escribió en 1849 que en Calbuco las tablas de alerce son tan comunes que sirven de moneda y están recibidas como tal en todos los almacenes y bodegones $^{64}$, lo que se observó también a fines del siglo $\mathrm{XIX}^{65}$. Es decir, fue moneda en Chiloé durante, al

60 Plano general de costos y auxilios para la ejecución del proyecto de defensa del puerto de Valdivia, Valdivia, 8 de octubre de 1785, Mariano Pusterla, en AN, Fondo Varios, Vol. 284, cuad. 3.

61 Fonck, Francisco, Viajes de fray Francisco Menéndez a Nahuelhuapi, op. cit., p. 77 (nota de Fonck).

62 Sobre el corte y las cualidades de las diversas especies de maderas en Chile. Artículo dirigido a la Facultad de Ciencias por una persona residente en Chiloé, Anales de la Universidad de Chile, Primera Serie, 1850, pp. 195-196.

63 Martinic, Mateo, 2005, De la Trapananda al Áysen, Pehuén Editores, Santiago, p. 114.

64 Gay, Claudio, 1849, Historia Física y Política de Chile, T.V, Botánica, París-Santiago, p. 408.

65 Francisco Fonck, Diarios de fray Francisco Menéndez, T. I, Viajes a la cordillera, op. cit., dice en p. 20: "Otro rasgo muy original es el uso general de tablas de alerce como medio circulante en lugar del dinero en las transacciones comerciales y privadas del Archipiélago". menos, dos siglos. En Calbuco decir una tabla era lo mismo que decir un real, aunque en realidad 4 tablas equivalían a un real en $1842^{66}$. Calbuco era el centro de operaciones de quienes cortaban alerce en el seno de Reloncaví, por entonces despoblado, en un sector llamado Astillero, en Cayenel, que era desde donde se hacían tablas con los troncos abandonados de alerzales ya exportados en el XVIII, o se internaban los chilotes para ir a las manchas de alerces vivos, descrito y graficado en un plano por Bernardo Philippi. Eso si, no recorrían los chilotes el cercano lago Llanquihue, lugar que creían dominado por brujos, y por lo mismo no explotaban sus alerzales ${ }^{67}$. En los años siguientes los alemanes se beneficiaron de la madera: en la recién fundada Puerto Montt los primeros colonos obtuvieron como ayuda del gobierno, además de otros efectos, 300 tablas de alerce por cada familia para construir su casa ${ }^{68}$, pero además la colonia de Puerto Montt tuvo como principal fuente de ingreso la venta de la madera de alerce, que según datos disponibles, se vendió por un total de 57.000 pesos en 1856 y 60.000 pesos en $1857^{69}$. Los chilotes se empleaban como tableros en Puerto Montt a fines del siglo XIX: las tablas todavía se cortan a mano, tal como se hacía antiguamente, y este trabajo se contrata como pan caliente. Los chilotes pasan por toda la colonia con su serrucho al hombro y se ofrecen para cortar madera.

Durante el siglo XIX, el principal ingreso fiscal en la provincia de Chiloé fueron los derechos que se pagaban por el embarque del alerce. Y esos derechos se seguían, como antaño, pagando en tablas, que se recibían a un cuarto de real, con lo cual, el intendente de Chiloé cobraba y disponía de tablas como patrimonio. Por ejemplo, como balance del año 1843, la tesorería de Chiloé tenía 186.151 tablas de alerce, y 120.000 de ellas se destinaron a la construcción de edificios fiscales ${ }^{70}$. Por orden de la autoridad en Santiago, las restantes 60.000 tablas fueron puestas a disposición del intendente para ser

66 Philippi, Bernardo, op. cit., p. 19.

67 Pioneros del Llanquihue, 1852-2002, p. 46.

68 Ibidem, p. 91

69 Crónica de la presencia alemana en el sur de Chile, publicada en 75 Jahre Deutschtum in Chile, 1927, en Pioneros del Llanquihue, 1852-2002, p. 36.

70 AN, Intendencia de Chiloé, Vol. 10. Carta de 14 de febrero de 1844 . 
distribuidas entre los vecinos mas pobres de Ancud, a causa de un enorme incendio ocurrido en enero del año siguiente en esa ciudad ${ }^{71}$. En 1868 las 100 tablas de alerce se pagaban a 4,50 pesos, precios puestos al costado del buque, y los tablones, 12,50 el ciento. Ese año se decía que las maderas más apreciadas eran el alerce, ciprés y lingue, cuando el año anterior se habían cargado 50 buques en Ancud $^{72}$. Veinte años más tarde, en 1886, las 100 tablas costaban el doble, entre 8 y 12 pesos según el largo y el grosor, dice Julius Held ${ }^{73}$, y para 1896 , fecha en que escribe Fonck, el precio de cada una variaba entre 6 y 12 centavos $^{74}$. Para entonces, la explotación del alerce era ejecutada por compañías, que pagaban a sus trabajadores en dinero, como la Compañía Explotadora y la de Oelkers Hermanos, ambas de Quemchi ${ }^{75}$. Fray Francisco Menéndez, que en dos ocasiones exploró la Sierra Nevada frente a Chiloé y en cuatro ocasiones hizo expediciones al lago Nahuelhuapi, conoció de cerca los alerzales de Reloncaví, a fines de siglo XVIII, el valor que se le daba a la madera y la envergadura de su explotación. El franciscano alerta sobre su pronta desparición de continuarse el ritmo de su tala, y sugiere en su escrito imitar al gobierno de los Estados Unidos en declarar inviolables ciertos bosques y distritos: $s i$ no se toma medida análoga desaparecerá el alerce en época no lejana del territorio de Chile ${ }^{76}$. Según Weber, que escribe en 1903, el mercado de las tablas se terminó saturando en Valparaíso.

En el XIX se agregó el corte del ciprés en las islas Guaitecas. Su uso era principalmente para la fabricación de durmientes de ferrocarril -300.000 durmientes anuales en $1871^{77}-$, actividad que al parecer tiene como precursor o pionero a Westhoff, un alemán que se estableció en 1859 en Ancud para

71 AN, Intendencia de Chiloé, Vol. 10. Carta de 17 de febrero de 1844.

72 El Chilote, Ancud, 10 de septiembre de 1868.

73 Carta de Julius Held, fechada el 18 de septiembre de 1886, en Pioneros del Llanquihue, 1852-2002, p. 267.

74 Fonck Francisco, Diarios de fray Francisco Menéndez, T. I, Viajes a la cordillera, op. cit., p. 23.

75 La Cruz del Sur, Ancud,10 de octubre de 1901.

76 Menéndez, Francisco, Diarios de fray Francisco Menéndez, T. I, Viajes a la cordillera, op. cit., p. 23.

77 Simpson, Enrique, 1875, Exploraciones hechas por la corbeta 'Chacabuco' al mando del capitán de fragata Enrique Simpson, en Anuario Hidrográfico de la Marina de Chile, Tomo I, Imprenta Nacional, Santiago. explotar la riqueza cipresera de las islas Guaitecas, y proveer de durmientes de ferrocarril a Perú. Puso un centro en una de las islas, empleó a 3.000 hombres en diversas explotaciones y llegó a disponer de una flota de 200 goletas $^{78}$, en cuyo puerto, Melinka y en los mejores tiempos solía haber 10 o más buques a la carga. En 1868, época de prosperidad, el ciento de madrinas de ciprés se embarcaba a 30 pesos; el de cuartones a 14; el de viguetas a 75; tijerales a 40 pesos; y por útimo, los 100 durmientes se vendían a 56 pesos. Para entonces, la madera de ciprés se vendía en más tipos y mucho mas caro que el alerce ${ }^{79}$. A comienzos del XX la prosperidad había pasado y se le veía como triste a la capital de las Guaitecas, cuando tras largos intervalos iba uno que otro buque a cargar ciprés ${ }^{80}$. Hubo otros empresarios del ciprés que continuaron la senda abierta por Westhoff, como Ciriaco Álvarez, chonchino, que estableció un astillero en el estuario del río Aysén ${ }^{81}$. A diferencia del alerce, de explotación más antigua, tradicional, individual y espontánea, la del ciprés de las Guaitecas fue impulsada y coordinada por empresarios habilitadores ${ }^{82}$, y también arrasó con los bosques, como era ya notorio en 1854, cuando Vicente Pérez Rosales señalaba que se malgastaba el ciprés, inutilizando para el mezquino trabajo de un tablón, que aquí llaman madrina, los árboles nuevos y de más lozanas esperanzas; y para postecillos, los corpulentos y demás como extracción, y recomendaba que se prohiba el corte de cipreses en las islas Guaitecas ${ }^{83}$. Pero continuó. Weber, que escribe en 1903 señala que en verano salían de Chiloé más de 2.000 madereros a cortar ciprés en la islas Chonos $^{84}$. La tala se realizó en conjunto con otras actividades económicas como la minería del oro o la caza del lobo marino, y fue el inicio de la explotación económica y colonización de la actual región de Aysén, siempre vista como una cantera de recursos inagotables. El hacha y las quemazones fueron extinguiendo los alerzales

78 Martinic, Mateo, op. cit., p. 112-113.

79 El Chilote, Ancud, 10 de septiembre de 1868.

80 Weber, Alfredo, op. cit., p. 58.

81 Idem.

82 Carreño, Luis, 1996, Explotación y depredación de la región de Aysén en el siglo XIX, Impactos 84: 2-5, p. 5.

83 Vicente Pérez Rosales al Ministro de Estado en el Departamento del Interior, Santiago, 22 de mayo de 1854, publicado en Pioneros del Llanquihue, 1852-2002, p. 298.

84 Weber, Alfredo, op. cit., p. 57. 
y cipresales, hasta que los alerces vivos fueron declarados Monumento Nacional, por decreto de 1 de octubre de 1976, prohibiéndose su corte. Estas especies son protegidas principalmente en parques nacionales, reservas forestales y en el Monumento Nacional Alerce Andino, pero también en reservas privadas $^{85}$.

\section{EL TABLERO}

El XIX fue el siglo del hachero, del tablero, de las tejuelas de alerce, del guaitequero, del cipresero, y también el siglo de la depredación del manto boscoso de la isla de Chiloé y territorios continentales $e$ insulares adyacentes. Todo este mundo vegetal era dominio del hachero, y tal como en los siglos coloniales, en el diecinueve predominaban los apellidos veliches entre estos especialistas del bosque, hijos de la cultura de la madera ${ }^{86}$, o de la cultura del alerce ${ }^{87}$, cuyo oficio era llamado también de tableros. Todo indígena era tablero, es decir, cuando debía talar sabía hacerlo. En el siglo XVIII veliches encomendados tributaban en especies con tablas de alerce $^{88}$. Pero también españoles (de los llamados pobres) y mestizos eran tableros, entre los que se encontraban los soldados de la tropa reglada de los fuertes de la provincia (Calbuco, Carelmapu, Maullín, Chacao, y más tarde, San Carlos), que desde muy antiguo combinaban sus funciones militares con la de hacheros. Esta actividad les permitía el sustento mientras llegaba su paga, que era en especies, en el barco anual que trasportaba el Real Situado desde Lima, pero que también lo hacían por requerimiento

85 Véase Gayoso, Jorge y Bastienne Schlegel, 1988, Alerce (Fitzroya cupressoides) como Monumento Natural: un factor de desarrollo económico en la X Región de Los Lagos, Chile, Bosque 19 (2): 85-94.

86 Marino, Mauricio y Cipriano Osorio, 1983, Chiloé, cultura de la madera. Proceso a los brujos, sin datos de edición. También Marino, Mauricio, 1985, Chiloé: economía, sociedad, colonización, Ediciones Víctor Naguil, Ancud.

87 Morales, Héctor, La cultura del alerce, op. cit.

88 Pueden verse las cantidades en el Archivo General de la Nación de Lima. Por ejemplo, en el año 1789 había 1.739 tributarios en 62 capillas, que pagaban en tablas y jamones. AGN, Perú, Cajas Reales de Chiloé, Leg. 411, cuad., 146. Véase también Urbina, Rodolfo, 2004, Población indígena, encomienda y tributo en Chiloé: 1567-1813. Política estatal y criterios locales sobre el servicio personal de veliches $y$ payos, Monografías Históricas, № 16, Ediciones Universitarias de Valparaíso. de los gobernadores, que aprovechaban la mano de obra de los soldados para provecho de las Cajas Reales, o del suyo propio ${ }^{89}$. Eso explica que a fines del XVII Tomás O"Higgins escriba que navegaban los españoles e indios en piraguas hasta la cordillera de Polhue en que cortan las tablas de alerce $e^{90}$. Indios o chilotes iban en primavera y verano a las tierras continentales, a los pies de la Cordillera de los Andes, que llamaban Cordillera Nevada, a la tala del alerce ${ }^{91}$. Toda esa geografía es de topónimos indígenas, lo que revela hasta hoy un ámbito casi exclusivamente chilote, con predominio de la cultura indígena. Experto tanto en mares como en bosques, el tablero chilote -y el tejuelero del siglo $\mathrm{XX}^{92}$, que ya no explota el alerce sino el canelo y otros árboles, y al que le dedica una semblanza Antonio Cárdenas Tabies ${ }^{93}$ - recoge el conocimiento indígena de su espacio geográfico y del bosque, y explota el alerce para el comercio a la manera europea.

Alfredo Weber, que conoció Chiloé en los últimos años del siglo XIX, captó la relación del chilote con su bosque. Dice que el chilote es por naturaleza soñador y aventurero, poeta rústico sin palabras. El bosque ejerce sobre él una extraña fascinación por su grandeza, misterio y silencio, y a la verdad -dice- se comprenden aquellos madereros que hacha en mano se lanzan a esa vida de privaciones y penas cortando las tablas a pulso para llevarlas al hombro por las sendas mas escabrosas atravesando bosques y pantanos ${ }^{94}$. El cuadro-agrega Francisco Fonck en 1900- no deja de ofrecer sus atractivos

89 Existe abundante documentación sobre este comercio en el citado Fondo Cajas Reales de Chiloé, existente en el AGN, Lima, Perú.

90 Viaje del capitán de ejército don Tomás O"Higgins de orden de virrey de Lima, el marqués de Osorno, 1796-1797. AN, Fondo Antiguo, Vol. 33, fjs. 29

91 Véase a Mansilla, José, 1991, Los alerceros calbucanos entre 1835 -1850, Boletín Literario Araña Gris 20: 2830. El mismo en 1992, Cuadernos de Caicaén. Historia y folklore de las islas 6: 45-49.

92 Véase el trabajo de recopilación visual y documental del oficio de tablero, en un proyecto Fondart, del ingeniero forestal y tablero aysenino Carlos Castillo Levicoy y otros, "La tejuela artesanal en los bosques, un oficio en extinción: Testimonios de Identidad, Historia y Patrimonio Cultural de la región de Aysén", 2011, texto inédito, y del mismo investigador: www.tejueleoenpatagonia.cl.

93 Cárdenas, Antonio, 1971, Los guaitequeros, personajes folklóricos de Chiloé, Talleres "Fournier", Rancagua, pp. 28 y 29.

94 Weber, Alfredo, 1903, op. cit., p. 52. 
y cierto aire de poesía ${ }^{95}$. También, la destreza con el hacha era inherente al chilote.

Los chilotes aprovecharon los montes continentales desde fines del siglo XVI, cuando comenzó la demanda de alerce en Chile y Perú. Pero aquel bosque frío e inhóspito no poseía ese misterioso sentido que para el isleño tenía el monte insular, poblado de seres de la mitología y al que se acercaba con cautela. Por eso también, sin reparo alguno se transformó en predador del continente, aunque no lo colonizó y no lo hizo por las mismas razones que no colonizó el interior de la Isla Grande y costa occidental de la misma, es decir, por la aspereza y montuosidad de los terrenos; por la inexistencia de lugares propicios a la habitabilidad humana y a la agricultura; por el clima más riguroso que en las islas; por las más copiosas lluvias; por la soledad de aquellos parajes; $y$ por la poca disposición de los chilotes al continente. Por eso, sólo existieron campamentos temporales o astilleros mientras duraban las faenas. Las faldas de la Cordillera se mantuvieron desiertas y sin población estable hasta principios del siglo XX.

Los tableros eran originales tipos fronterizos. Salían de sus pueblos con los aperos y matalotaje tradicionales, desde el siglo XVII a comienzos del XX, porque en esto no se mudó casi nada a lo largo de los siglos. Cargaban la dalca, el lanchón o la chalupa con pescado seco, sartas de choros, jamones ahumados, chiguas de papas, harina mezclada con linaza para preparar el también tradicional ulpo o guampada. Este era el alimento principal en las expediciones fuera de las islas ${ }^{96}$, y algunas veces era preparado por los tableros en las concavidades de las maderas elaboradas, cuya operación llaman ulpiar ${ }^{97}$. Llevaban también ollas, cafeteras, velas, cobijas de lana, aguardiente y una escopeta para defenderse "del león", pumas que podían bajar en verano hasta la misma costa continental en el área de Comau. En los siglos

95 Fonck, Francisco, Diarios de fray Francisco Menéndez, T. I, Viajes a la cordillera, op. cit., p. 20

96 Para sus expediciones por Patagonia Occidental, entre 1892 y 1902 , Hans Steffen contaba con un equipo de experimentados chilotes. Describió su comportamiento, su capacidad de trabajo, de resistir bajo la lluvia permanente, su habilidad en el caminar por terrenos disparejos, su aguante de la carga, y su salud inquebrantable, sólo mantenida en base a papas y al ulpo. La caracterización que da de ellos en nada parece haber variado desde que se referían a ellos, en estas mismas faenas, los exploradores coloniales.

97 Philippi, Bernardo, op. cit., p. 21. coloniales se zarpaba en dalcas, y en el XIX en goletas, chalupas o lanchones, para alcanzar la costa continental después de dos días de navegación tomando en cuenta las regulares paradas, que en veliche -la lengua indígena de Chiloé- llamaban quelcuñes. Era una vieja tradición. En el siglo XVIII Segismundo Güell lo describe así: se juntan 6 u 8 indios o pobres españoles y cada uno con un poco de harina que baste para 3 semanas, con su piragua navegan aquellos golfos arriesgados y van o a Reñihe o a Leteu, o a otra parte donde ellos saben que hay tales alerces ${ }^{98}$. Tres semanas dice también que tardaban en la faena Francisco Vidal Gormaz, en $1871^{99}$. Se instalaban los grupos en primavera y hasta el verano en un rincón oculto de algún fiordo -como vio Hans Steffen- para dirigir desde allí sus trabajos en el bosque, y los que quedaban en el campamento -mujeres e hijos- dejaban pastar su ganado, cazaban focas, recogían mariscos y pescaban ${ }^{100}$. Este habría sido el origen de algunos de los pueblos actuales ${ }^{101}$. Vidal Gormaz da información precisa sobre períodos de corte: un primer período desde mediados de septiembre, de tres semanas de duración, de quienes se regresaban en octubre a la siembra de las papas; un segundo período que se extendía desde principios de enero hasta principios de febrero, en que se volvía para la cosecha del trigo y la linaza; y una tercera salida de sólo 15 días en abril, volviendo a las islas a cosechar las papas ${ }^{102}$.

\section{LA MODALIDAD DE LA TALA}

Cada grupo de tableros llevaba un jefe, generalmente el más experto en la tala y conocedor del

98 Güell, Segismundo, Noticia breve y moderna del Archipiélago de Chiloé, de su terreno, costumbres de sus indios, misiones, escrita por un misionero de aquellas islas en el año 1769 y 70, en Hanisch, Walter, op. cit., p. 244.

99 Vidal Gormaz, Francisco, 1871, Exploraciones de la costa de Llanquihue y archipiélago de Chiloé, Anales de la Universidad de Chile 39, p. 55.

100 Steffen, Hans, op. cit., T. I, p. 45

101 Dice Steffen: "Estas residencias temporales y ocasionales dieron muy a menudo origen a poblaciones permanentes como las que observamos en las costas del fiordo de Reloncaví, en Ralún, y en la desembocadura del río Puelo, donde las casas y cortijos abarcan ya unos cuantos kilómetros tierra adentro. También en la desembocadura del Reñihue, en el Chaitén, en el Corcovado y en el curso inferior del Aysén algunas familias chilotas se han establecido de manera permanente". Steffen, Hans, op. cit., T. I, p. 46.

102 Vidal Gormaz, Francisco, op. cit., p. 55. 
paraje. Cuando no había un refugio levantado antes por otros tableros, se hacía una ramada, llamada astillero, una morada provisoria, como salida por encanto de la tierra, que después desaparece sin dejar rastros ${ }^{103}$, desde las que se preparaba la internación hacia los lugares de corte, cada vez más alejados de la costa.

Para la tala, se buscaban los sitios más accesibles. Si el río lo permitía, se navegaba por él hacia el interior, como se hacía en el río Coihuín, luchando contra la corriente con botes livianos y sin quilla, o en balsas tableras al regreso. Muchos perecían en el descenso del rápido Coihuín en el siglo XVIII, a pesar de su destreza y capacidad para estas tareas. El explorador científico Hans Steffen ${ }^{104}$, que en los años del cambio del siglo XIX al XX recorrió los faldeos cordilleranos entre los $41^{\circ}$ y $48^{\circ}$ de latitud sur, elogiaba la fortaleza, conocimiento y habilidad de estos chilotes marinos y hacheros que llevaba como auxiliares en sus entradas por aquellas espesuras. Los describe como gente de gran coraje y habilidad para internarse por los ríos rápidos de la zona, arrastrando los botes por medio de cuerdas desde las orillas y haciendo uso del mayor ingenio para vadear los caudalosos torrentes. No había mejores para explorar el bosque, navegar por los fiordos $y$ ensenadas piemontanas y soportar el clima ${ }^{105}$.

Primero había que detectar una mancha, se esperaba que no muy lejana de un sitio que pudiera servir de puerto de embarque, de río o de mar. El alerce se halla en manchas ${ }^{106}$, más o menos

103 Philippi, Bernardo, op. cit., p. 19.

104 Véase Pozo, José, 2005, Hans Steffen: maestro, geógrafo y pionero de la Patagonia Occidental, Universum 20 (1): 112-123.

105 Véase Urbina, M. Ximena, 2010, La navegación por los canales australes en la Patagonia occidental insular en los siglos coloniales: la ruta del istmo de Ofqui, Magallania 38 (2): 41-67.

106 Gunckel, Hugo, 1979, Vocablos populares técnicos relacionados con la industria del alerce en Chiloé y Llanquihue, Noticiario Mensual del Museo de Historia Natural 274275: 3-13, p. 10. Gunckel realizó este nutrido vocabulario relativo al alerce sobre la base de las fuentes publicadas, como Francisco Fonck, Claudio Gay, Carlos Juliet, Roberto Maldonado, José de Moraleda y Francisco Vidal Gormáz, entre otros, y algunos vocabularios mapuches y veliches. Toda la información anterior la enriqueció el autor con el conocimiento adquirido en varias excursiones botánicas a los alerzales de la cordillera Pelada, y de Chiloé, ésta última en 1946. extensas y frecuentes, y raras veces forma verdaderos bosques ${ }^{107}$. Localizada, se hacía el sendero o cuicuy, siempre estrecho y resbaloso, para conectar el sitio de la tala -los chilotes decían que iban a las minas ${ }^{108}$ - con el astillero o lugar de embarque, y conducir de regreso las tablas al hombro. Estos mismos caminos servían a otros, tableros menos diestros y emprendedores -dice Fonck-que van en estaciones siguientes, y usan el cuicuy para aprovechar los palos sobrantes dejados por los otros y sacar algunas tablas. En el seno de Reloncaví, por ejemplo, lugar de antigua explotación, era conocido el camino del alerce, un angosto sendero de cuicuyes a través de la espesura que ascendía en agudo zig-zag hasta las altas montañas ${ }^{109}$. La ruta a la mancha podían ser uno o dos días de camino por terrenos quebrados y pantanosos, de sotobosques tupidos. Internarse era trepar la montaña, porque el lahuan o alerce se hallaba a unos 500 metros sobre el nivel del mar, que era donde los ejemplares alcanzaban mayor altura y grosor. A la cabeza del grupo el machetero abría la senda desbrozando el camino para dibujar una precaria, tortuosa e inclinada ruta, haciendo picada, es decir, marcando la senda con hachazos en los troncos de los árboles, para así poder guiarse al regreso ${ }^{110}$. De cuando en cuando, el necesario volteo de algunos árboles que aplastasen a otros de menor tamaño y a las quilas, y sobre esos troncos caminabase apoyándose en una larga vara111.

Se transitaba por un denso bosque de tres pisos. Primero, la vegetación baja de quilas, otros arbustos y matorrales que exigían del machete; luego el segundo nivel, formado por coigües, mañíos y corpulentos robles, superados todos en altura por el tercer nivel de los majestuosos alerces. En estos terrenos quebrados y de vegetación densa había que tener vista panorámica del sector para distinguir las manchas. A esto se le llamaba altear, es decir, situarse en lo alto del cerro o en la copa de algún espigado árbol para otear el paisaje ${ }^{112}$. El alteo no podía ser difícil: se trataba de gigantes.

Si era una mancha visitada antes, se localizaban los ejemplares picados el año anterior, es

\footnotetext{
107 Fonck, Francisco, op. cit., p. 20.

108 Philippi, Bernardo, op. cit., p. 19

109 Steffen, Hans, op. cit., Tomo I, p. 95.

110 Gunkel, Hugo, op. cit., p. 11.

111 Philippi, Bernardo, op. cit., p. 20.

112 Maldonado, Roberto, op. cit., p. 118.
} 
decir, los que se dejaban preparados para el corte. Picar un alerce significaba hacerle orificios para que escurriera la savia y hallarlos secos al año siguiente, y la madera en mejores condiciones de ser usada. Al estilar, el tronco cambiaba de color, tomando un tono plateado, fácil de distinguir por el alteador que escudriñaba la mancha desde lo alto. Era la costumbre y conocimiento del tablero adquirido desde los siglos coloniales, como lo describe Güell ${ }^{113}$. En la mancha, el tablero chilote estudiaba el entorno y el procedimiento a seguir. Se distinguían tres cortezas en el tronco: la primera, de textura leñosa; la segunda, colorada y filamentosa, que era se desprendía con facilidad del árbol en forma de largas tiras, la llamaban estopa, era cosechada en verano y vendida en los mercados locales, porque era inmejorable para calafatear ${ }^{114}$; la tercera corteza era el cochai que se usaba para tapar costuras de las dalcas. Entre el cochai y el tronco sólido estaba la savia o resina aromática que los chilotes llamaban incienso, porque se quemaba en los actos religiosos de las capillas del Archipiélago. El método para extraer esta savia era picar el tronco y dejar una vasija para recibir el líquido que se escurría lentamente, el que se recogía al año siguiente. Se elegían determinados ejemplares, que eran los alerces más fáciles de voltear y de mejor calidad, es decir, más dóciles para rajar en tablas para obtener así en poco tiempo el mayor número de ellas ${ }^{115}$. Con algunos golpes dados al tronco con el hacha, sabían por el sonido si estaba sano o podrido ${ }^{116}$. Pero también se consideraba la ubicación del ejemplar elegido. Como normalmente estaba en plena pendiente, debía saberse con precisión cómo caería luego de derribado, y en qué posición quedaría. La pericia de los hacheros consistía en hacerlo caer horizontalmente a la quebrada y calcular que quedara sostenido por los troncos de los demás alerces. Sólo así podía estar en condiciones de ser trabajado. Esta operación necesitaba de seis o más hombres que hacheaban el tronco al mismo tiempo y a la misma altura, lo que se conseguía mediante un andamio de unos tres metros de alto que demandaba un día de trabajo, andamios que en lenguaje

113 Güell, Segismundo, en Hanisch, Walter, op. cit., p. 244.

114 Este y los siguientes conceptos en Gunckel, Hugo, op. cit., p. 5 y 8.

115 Fonck, Francisco, Diarios de fray Francisco Menéndez, T. I, Viajes a la cordillera, op. cit., p. 21.

116 Weber, Alfredo, op. cit., p. 55. de tablero se llamaban caballos. En el mismo sitio de corte se construía una ramada o cuartel para el descanso y alojo, plantaban una cruz como símbolo de esperanza, dice Alfredo Weber ${ }^{117}$, y todo aquel ámbito de trabajo tomaba el nombre de astillero ${ }^{118}$.

Toda mancha tenía variados tipos de lahuanes según sus características y que el tablero podía distinguir, como se aprecia en su rico legado lingüístico que da cuenta de su relación con el entorno y de la ausencia de términos castellanos en lo relativo a estas tareas, como si la cultura de la madera hubiera sido dominio exclusivo del chilote veliche. Cude-cude llamaban al alerce descogollado, y sólo cude al desgajado, pobre de copa, pero que sigue viviendo ${ }^{119}$. Cude-petriu era el seco e inútil para su aprovechamiento maderero; denominaban palos verdes a los de corta edad y concañ los lahuanes viejos y dañados, inutiles para beneficiarse de ellos. Los tronchados recibían el nombre de mechung, y regañata el derribado de raíz; ala el rajado y huiñor el de tronco inclinado. El ejemplar de tronco irregular y deforme recibía el nombre de pollera-quechu, y peñeng el que crecía con dos troncos unidos, siendo uno menor que el otro. En cambio, cuando los dos troncos unidos eran iguales, se llamaba chanchui.

Un robusto ejemplar de 14 metros de circunferencia necesitaba de un día o más para que un grupo de 6 ó 7 hombres bien distribuidos sobre el caballo pudiera voltearlo para luego convertirlo en tablas. Se comenzaba por cabecearlo, es decir, dejar plana la base del tronco para luego proceder a cuartonearlo. Para esto se usaba el hacha y el mazo. Primero se rayaba, es decir, se hacía una fisura en la base donde introducía una cuña resistente, de luma, mañío o tepu, que bien puesta y hábilmente presionada, abría y rajaba el tronco haciendo saltar la tabla a todo lo largo del troco, por ser éste de una hebra, resultando así tablones, llamados metan (cada una de las dos mitades semicilíndricas) y huichacones. Trabajo similar se hacía con cada tablón, metiéndole una cuña en la punta y a los dos golpes saltaban más tablones y finalmente las tablas de las dimensiones acostumbradas, y cuya operación llamaban partir por chellev, hasta sacar cuantas se

117 Idem.

118 Moraleda, José, op. cit., p. 132.

119 Este y todos los demás conceptos en Gunckel, Hugo, op. cit. 
podían obtener de aquel tronco. Un tronco se faenaba según la utilidad que se le daría a la madera: para hacer tablas se cortaba el tronco a 2,20 metros de largo, y si era para hacerlo mochos o durmientes, de 2,44 metros; por último, para tablones el largo era de 2,31 metros, medidas de fines del siglo XIX ${ }^{120}$. En quince días se faenaba un lahuan de buen grosor y altura, y luego, se reiniciaba la operación de derribar otro árbol.

Concluido el trabajo se juntaban todos los paquetes de tablas amarradas y se conducían a la playa para ser embarcados, participando en ello mujeres e hijos ${ }^{121}$. Las tablas o tablones se llevaban de hasta 40 por persona ${ }^{122}$, por una conducción terrestre que era lo más pesado porque desde los talleres debían cruzar cerros, quebradas, pantanos y toda clase de asperezas con la carga a cuestas. Era un viaje lento pero más seguro si se iba a pie. Más rápido y arriesgado si se podía usar una vía fluvial, por ríos que en esas cordilleras se precipitan veloces, y donde la carga se echaba sobre balsas tableras construidas para tal fin, o en bote. Pero lo normal era bajar por tierra siguiendo el elemental sendero sobre quebradas profundas, equilibrándose sobre cuicuyes resbalosos, rumbos que, según Steffen, eran sólo transitables por nativos, que iban descalzos o con tamangos hechos de cuero de buey sin curtir, aunque se pondera que con este calzado tan flexible y seguro el pie se aferra bien tanto a las escabrosidades del terreno como entre los palos del bosque. Por eso es el calzado común, dice, de los montañeses y madereros de todo Chiloé123. Agrega Hans Steffen: los indígenas y mestizos se movilizan por semejantes senderos -que el tránsito y la humedad hacen resbaladizos- con una seguridad y rapidez sorprendentes ${ }^{124}$. Los hombres descendían en largas hileras de a uno en fondo, llevando la carga de tablas sobre el hombro sujeta con una mano, mientras la otra iba asida a un palo a manera de bastón y que llamaban caballito y cuyo extremo tenía la forma de horqueta. Cada una hora de camino, más o menos se hacía una descansada, poniendo la carga en el suelo, pero si se trataba sólo de mudar la carga de un hombro a otro, sin

\footnotetext{
120 Vidal Gormaz, Francisco, op. cit., p. 55.

121 Idem.

122 Steffen, Hans, op. cit., T. I, p. 96.

123 Maldonado, Roberto, op. cit., p. 106.

124 Steffen, Hans, op. cit., T. I, p. 96
}

detenerse, se llamaba cantutún, que equivalía a un cuarto de hora ${ }^{125}$. Claudio Gay señala que ambas palabras, tan comunes entre los alerceros, eran parte del lenguaje cotidiano de Calbuco usándolas para señalar una distancia cualquiera ${ }^{126}$. Años después, en 1871, Vidal Gormaz apunta que las descansadas son cada tres cuadras, pero que sólo consisten en clavar de punta la carga, respirar dos o tres veces, y volver a alzarla cambiando de hombro, continuando la marcha ${ }^{127}$, mientras que, si el camino es largo, cada doce descansos se hace una pausa de cerca de media hora ${ }^{128}$. Y así se llegaba finalmente a la playa donde estaban los chalupones, la ramada y las mujeres junto al fuego. Para fines del siglo XVIII señala el autor de la Noticia breve y moderna que las tablas se reunían y contaban en la playa, y se repartían en partes iguales entre los hombres, para ser conducidas y vendidas individualmente en Chiloé, cantidad que era de unas 100 a 140 tablas por cada hombre, en el trabajo de una semana, y que era vendida a 3 pesos el ciento, la mitad en dinero y la mitad mercancía ${ }^{129}$. Entonces, al día siguiente se cargaban las embarcaciones y se navegaba al pueblo justo a tiempo para la cosecha de papas. Así era la vida del tablero chilote en 1897.

\section{FUENTES DE CONSULTA}

a) Inéditas

Biblioteca Nacional de Santiago: Fray Gregorio de León, Manuscritos Medina, Tomo 99.

Archivo Nacional de Santiago: Viaje del capitán de ejército don Tomás O"Higgins de orden de virrey de Lima, el marqués de Osorno, 1796-1797. Fondo Antiguo, Vol. 33, f. 29.

Plano general de costos y auxilios para la ejecución del proyecto de defensa del puerto de Valdivia, Valdivia, 8 de octubre de 1785, Mariano Pusterla. Fondo Varios, Vol. 284, cuad. 3.

Intendencia de Chiloé, Vol. 10.

Archivo General de Indias de Sevilla: El cabildo de Castro. Castro, 16 de abril de 1743. Audiencia de Chile, 102.

125 Gunkel, Hugo, op. cit., p. 4.

126 Gay, Claudio en Lara, Antonio, op. cit, p. 96.

127 Vidal Gormaz, Francisco, op. cit, p. 55.

128 Idem.

129 Ibidem, p. 36 
Archivo General de la Nación Perú: Fondo Cajas Reales, Cajas Reales de Chiloé, Legajo 407, cuaderno 108; Leg. 411, cuad.146.

Prensa: El Chilote (Ancud) y La Cruz del Sur (Ancud).

b) Impresos

ASTA-BURUAGA, F. 1899. Diccionario geográfico de la república de Chile, Segunda Edición, corregida y aumentada, sin datos editoriales, Santiago (primera edición en 1867).

CARVALLO Y GOYENECHE, V. 1865. Descripción históricojeográfica del reino de Chile por don Vicente Carvallo i Goyeneche, precedida de una biografía del autor por don Miguel L. Amunátegui. En Colección de historiadores de Chile y de documentos relativos a la historia nacional, MEDINA, José Toribio, Tomo IX, Santiago (comprende los tomos VIII, IX y X).

DARWIN, C. 1945. Viaje de un naturalista alrededor del mundo, Librería El Ateneo, Buenos Aires.

FONCK, F. 1896. Diarios de fray Francisco Menéndez, Tomo I, Viajes a la cordillera, Imprenta Niemeyer, Valparaíso. 1900. Viajes de fray Francisco Menéndez a Nahuelhuapi, Imprenta Niemeyer, Valparaíso.

GAY, C. 1849. Historia Física y Política de Chile, Tomo V, Botánica, París, en casa del autor, Chile, Museo de Historia Natural de Santiago.

GONZÁLEZ DE AGÜEROS, P. Descripción historial de Chiloé, 1791. Introducción y notas de Isidoro Vázquez De Acuña, 1988, Instituto de Investigaciones del Patrimonio Territorial de Chile, Universidad de Santiago.

GÜELL, S. Noticia breve y moderna del Archipiélago de Chiloé, de su terreno, costumbres de sus indios, misiones, escrita por un misionero de aquellas islas en el año 1769 y 70, en HANISCH, Walter, 1982, La isla de Chiloé, capitana de rutas australes, Santiago, Academia Superior de Ciencias Pedagógicas de Santiago.

LAGUNAS, A. 1897. Memoria del ayudante de la comisión. En Estudios geográficos e hidrográficos sobre Chiloé, MALDONADO, Roberto, Establecimiento poligráfico Roma, Santiago.

MALDONADO, R. 1897. Estudios geográficos e hidrográficos sobre Chiloé, Establecimiento poligráfico Roma, Santiago.

MORALEDA, J. 1888. Exploraciones geográficas e hidrográficas, Imprenta Nacional, Santiago.

PHILIPPI, B. Relación del descubrimiento del lago Llanquihue (1842), en Pioneros del Llanquihue, 1852-2002, 2002 , Liga Chileno-Alemana, Santiago.

RIBERA, LÁZARO DE. 1897. Discurso que hace el alférez don Lázaro de Ribera, ingeniero delineador, sobre la provicia de Chiloé...(1782). En Cinco relaciones jeográficas e hidrográficas que interesan a Chile, ANRIQUE, Nicolás, Imprenta Elzeviriana, Santiago.

RODRÍGUEZ BALLESTEROS, J. 1901-1904. Revista de la guerra de independencia de Chile, 1813-1826. En Colección de historiadores y documentos relativos a la independencia de Chile, MEDINA, José T., Vol. 6, Imprenta Cervantes, Santiago.

ROSALES, DIEGO DE.1877. Historia General del Reino de Chile, Flandes Indiano. Imprenta El Mercurio, Valparaíso.

SCHWAZENBERG, J. y A. MUTIZÁBAL. 1926. Monografía geográfica e histórica del archipiélago de Chiloé, Editorial Nascimento, Santiago.

SIMPSON, E. 1875. Exploraciones hechas por la corbeta Chacabuco al mando del capitán de fragata Enrique Simpson. En Anuario Hidrográfico de la Marina de Chile 1, Imprenta Nacional, Santiago.

1850 Sobre el corte y las cualidades de las diversas especies de maderas en Chile. Artículo dirigido a la Facultad de Ciencias por una persona residente en Chiloé, Anales de la Universidad de Chile, Primera Serie.

STEFFEN, H. Patagonia Occidental. Las cordilleras patagónicas y sus regiones circundantes, Reeditado en 2008, de la edición de 1844 por Eugenio Aspillaga y Luis Catalán.

VIDAL GORMAZ, F. 1871. Exploraciones de la costa de Llanquihue y archipiélago de Chiloé, Anales de la Universidad de Chile 39, Santiago.

WEBER, A. 1903. Chiloé: su estado actual, su colonización, su porvenir. Con un mapa que indica las colonias extranjeras y los terrenos colonizables, Imprenta Mejía, Santiago.

\section{BIBLIOGRAFÍA}

CÁRDENAS, A. 1971. Los guaitequeros, personakes folklóricos de Chiloé. Talleres Fournier, Rancagua.

CARREÑO, L. 1996. Explotación y depredación de la región de Aysén en el siglo XIX. Impactos 84: 2-5.

Crónica de la presencia alemana en el sur de Chile, publicada en 75 Jahre Deutschtum in Chile. 1927. en Pioneros del Llanquihue, 1852-2002, Liga Chileno-Alemana, Santiago.

DONOSO, C., R. GREZ y V. SANDOVAL. 1990. Caracterización del tipo forestal alerce, Bosque 11 (1): 21-34.

GAYOSO, J. y B. SCHLEGEL. 1988. Alerce (Fitzroya cupressoides) como Monumento Natural: un factor de desarrollo económico en la X Región de Los Lagos, Chile, Bosque 19 (2): 85-94. 
GUARDA, G. 1974. El gobierno de Valdivia (1645-1820), Boletín de la Academia Chilena de la Historia 88: 117-162. 1990. Flandes Indiano. Las fortificaciones del reino de Chile, 1541-1826. Ediciones Universidad Católica de Chile, Santiago.

GUNCKEL, H. 1979.Vocablos populares técnicos relacionados con la industria del alerce en Chiloé y Llanquihue. Noticiario Mensual del Museo de Historia Natural 274-275: 3-13.

GRENIER, P. 1984. Chiloé et les chilotes. Marginalité et dépendance en Patagonie chilienne. Ediciones EDISUD, Aix en Province, France.

HANISCH, W. 1982. La isla de Chiloé, capitana de rutas australes. Santiago, Academia Superior de Ciencias Pedagógicas de Santiago.

LARA, A. 1988. Alerces: gigantes milenarios del bosque chileno. En La tragedia del bosque chileno, Hoffmann, A. editora. Ocho Libro Editores, Santiago.

MANSILLA, J. 1991. Los alerceros calbucanos entre 1835 -1850. Boletín Literario Araña Gris 20: 28-30. El mismo artículo se reditó en 1992, Cuadernos de Caicaén. Historia y folklore de las islas 6: 45-49.

MARINO, M. y C. OSORIO. 1983. Chiloé, cultura de la madera. Proceso a los brujos, sin datos de edición.

MARINO, M. 1985. Chiloé: economía, sociedad, colonización. Ediciones Víctor Naguil, Ancud.

MARTINIC, M. 2005. De la Trapananda al Áysen. Pehuén Editores, Santiago.

MONTANDÓN, R.A. 1945. El alerce, preocupación ancestral del chilote. En Viaje 146:182-183.

MONTIEL, F. 2006. Los últimos constructores de artilugios de madera en Chiloé, Gobierno Regional de Los Lagos y CONAF.

MORALES, H. 2006. La cultura del alerce. En Conservación de la biodiversidad de importancia mundial a lo largo de la costa chilena. Comisión Nacional del Medio Ambiente, Ocho Libro Editores, Santiago, pp. 116-123.
OTERO, L. 2006. La huella del fuego. Historia de los bosques nativos. Poblamiento y cambios en el paisaje del sur de Chile. Pehuen Editores, Santiago.

POZO, J. 2005. Hans Steffen: maestro, geógrafo y pionero de la Patagonia Occidental, Universum 20 (1): 112-123.

TORREJÓN, F. 1996. Ecohistoria y destrucción en Chiloé continental: el caso del valle Vodudahue, 1700-1996. En Bases históricas del desarrollo regional de Chile. Facultad de Filosofía, Universidad de Chile, Santiago.

TORREJÓN, F., M. CISTERNAS y A. ARANEDA. 2004. Efectos ambientales de la colonización española desde el río Maullín al archipiélago de Chiloé, sur de Chile. Revista Chilena de Historia Natural 77: 661-677.

URBINA, R. 1986. Las tablas de alerce y los antiguos tableros chilotes. Creces 12: 19-21.

1990. El modo de comerciar de los chilotes a fines del siglo XVIII. En Economía y comercio en América Hispana, G. Bravo editor, Serie Nuevo Mundo: Cinco Siglos, № 5, Universidad de Chile, Santiago.

2004. Población indígena, encomienda y tributo en Chiloé: 1567-1813. Política estatal y criterios locales sobre el servicio personal de veliches y payos, Monografías Históricas, № 16, Ediciones Universitarias de Valparaíso.

URBINA, M. X. 2009. La frontera de arriba en Chile Colonial. Interacción hispano-indígena en el territorio entre Valdivia y Chiloé e imaginario de sus bordes geográficos, 1600-1800, Centro de Estudios Diego Barros Arana, de la Dirección de Bibliotecas, Archivos y Museos, y Ediciones Universitarias de Valparaíso.

2010. La navegación por los canales australes en la Patagonia occidental insular en los siglos coloniales: la ruta del istmo de Ofqui, Magallania 38 (2): 41-67.

VILLAGRÁN, C., A. LEÓN y F. ROIG. 2004. Paleodistribución del alerce y ciprés de las Guaitecas durante períodos interestadiales de la Glaciación Llanquihue: provincias de Llanquihue y Chiloé, región de Los Lagos, Chile. Revista Geológica de Chile 31(1):133-151. 
M. XIMENA URBINA 